\title{
GCU
}

Glasgow Caledonian

University

University for the Common Good

\section{Perceived stress and depression amongst older stroke patients: sense of coherence as a mediator?}

Guo, Li-Na; Liu, Yan-Jin; McCallum, Jacqueline; Soderhamn, Ulrika; Ding, Xian-Fei; Yv, SuYuan; Zhu, Yi-Ru; Guo, Yv-Ru

Published in:

Archives of Gerontology and Geriatrics

DOI:

10.1016/j.archger.2018.08.010

Publication date:

2018

Document Version

Author accepted manuscript

Link to publication in ResearchOnline

Citation for published version (Harvard):

Guo, L-N, Liu, Y-J, McCallum, J, Soderhamn, U, Ding, X-F, Yv, S-Y, Zhu, Y-R \& Guo, Y-R 2018, 'Perceived stress and depression amongst older stroke patients: sense of coherence as a mediator?', Archives of Gerontology and Geriatrics, vol. 79, pp. 164-170. https://doi.org/10.1016/j.archger.2018.08.010

\section{General rights}

Copyright and moral rights for the publications made accessible in the public portal are retained by the authors and/or other copyright owners and it is a condition of accessing publications that users recognise and abide by the legal requirements associated with these rights.

Take down policy

If you believe that this document breaches copyright please view our takedown policy at https://edshare.gcu.ac.uk/id/eprint/5179 for details of how to contact us. 


\section{Perceived Stress and Depression amongst Older Stroke Patients: Sense of Coherence as a mediator?}

Objective: This study aimed to explore the relationship between perceived stress, sense of coherence, and depression among older stroke patients.

Methods: A demographic questionnaire, the Perceived Stress Scale (PSS), the Sense of Coherence Scale (SOC) and the Center for Epidemiologic Studies Depression Scale (CES-D) were distributed to 3000 older stroke patients from Neurology wards in six large general hospitals, and 2907 individuals completed the survey. Data analysis consisted of correlation, multiple linear regression, and structural equation modeling. Results: The total score of the SOC and perceived stress showed a negative correlation $(r=-0.80, P<0.01)$, the total SOC of coherence and depression also resulted in a negative correlation $(r=-0.77, P<0.01)$, and the total score of the perceived stress and depression resulted in a positive correlation $(r=0.82, P<0.01)$. The results of multiple regression analyses indicated that SOC mediated the association between perceived stress and depression, and the influence of perceived stress on depression was decreased by $16.0 \%$ with in the sense of being out of control dimension and was decreased by $12.3 \%$ within the feeling of tension dimension when sense of coherence was added to the model. The structural equation model confirmed that the sense of coherence had a partial mediation effect between perceived stress and depression. Conclusion: SOC is the mediating variable between perceived stress and depression, and can reduce the influence of perceived stress on depression.

Key words: Older stroke patients; Sense of Coherence; Perceived Stress; Depression; Mediation effect 


\section{Introduction}

According to a report by the Chinese National Stroke Registry (Wang et al., 2011), strokes occurred in more than 7 million Chinese people in 2011, and more than $65 \%$ of them were old people. Rising trends have been observed in the morbidity and mortality of stroke, which causes a heavy burden to the national health care system (Zhou et al., 2017; Wang et al., 2011; Feigin et al., 2014; Yang et al., 2010). Patients who suffer with a stroke are usually exposed to a high level of perceived stress and are at higher risk of suffering from depression after the stroke, especially in the elderly (also called Post-Stroke Depression, PSD) than the general population and other patients (Robinson and Jorge, 2016). This is due to severity of impairment in activities of daily living, social functioning, and cognitive function (Fonarow et al., 2011). Some researchers reported that the incidence of $P S D$ in America ranges from $25 \%$ to $79 \%$ (Fonarow et al., 2009), and the rate of PSD is elevated at $62.2 \%$ in China (He et al., 2010). Depression can be defined as a mental disorder, with persistent sadness, loss of interest in daily living activities, difficulty concentrating, poor memory, loss of appetite, and lack of energy (Guo et al., 2017). In addition, depression and depressive symptoms can impair the older stroke patients' quality of life, and severe depression may lead to more suicide attempts among older stroke patients (Dou et al., 2015). Thus, depression and depressive symptoms of older stroke patients are a critical health issue not only for the older stroke patients themselves, but also for their family members or caregivers (Cameron et al., 2014). As a result, researchers around the globe have raised concerns about the prevention and treatment of PSD (Li et al., 2016; Karakus et al., 2017; Hackett and Pickles, 2014; MacHale et al., 1998; Kutlubaev and Hackett, 2014; De Ryck et al., 2014).

Perceived stress has been identified as a predictor of depression and depressive symptoms after stroke (Laures-Gore and Defife, 2013). With a high rate of morbidity, recurrence, disability and mortality, older stroke patients are highly exposed to perceived stress (Feigin et al., 2014). Unfortunately, perceived stress is increasing in China because of the financial burden, caregivers' exhaustion, and unsound healthcare 
system. Therefore, Chinese older stroke patients may be more vulnerable to depression and depressive symptoms compared with those in other diseases groups. According to the results of previous studies (Liu et al., 2016; Liu et al., 2017), perceived stress not only exerts a direct effect but also has an indirect effect on depression and depressive symptoms through triggering specific psychological responses. Therefore, in-depth research on both direct and indirect effects of perceived stress on depression and depressive symptoms should be conducted to develop more effective strategies for depression prevention and treatment.

Sense of Coherence (SOC) reflects a person's view of life and capacity to respond to stressful situations (Koelen et al., 2016). It is a personal way of thinking, being, and acting, with an inner trust, which leads people to identify, benefit, use, and reuse the resources at their disposal (Antonovsky, 1987). SOC consists of three elements: comprehensibility, manageability, and meaningfulness (Koelen et al., 2016). Research among older people shows that a strong SOC is related to good perceived health and quality of life (Eriksson and Lindström, 2006). People with a strong SOC reported fewer symptoms of illness, such as perceived depression, and SOC can also be used as a positive resource for combating depression (Li et al., 2015). In addition, SOC mediates the relation between perceived stress and depression among the Chinese elderly in urban communities (Liu et al., 2017). The potential impact of perceived stress on SOC and the associations between SOC and depression and depressive symptoms have not been examined among Chinese older stroke patients. In addition, whether or not SOC mediates the association between perceived stress and depression and depressive symptoms among Chinese older stroke patients has not been confirmed. It is important to understand the effect among Chinese older stroke patients on this association in order to effectively prevent and treat depression and depressive symptoms.

In light of the above concern, the present study began with the following hypotheses: hypothesis $1\left(\mathrm{H}_{1}\right)$, perceived stress will be positively and directly related to depression; hypothesis $2\left(\mathrm{H}_{2}\right)$, perceived stress will be negatively and directly related to SOC; hypothesis $3\left(\mathrm{H}_{3}\right)$, SOC will be positively and directly related to 
depression; and hypothesis $4\left(\mathrm{H}_{4}\right)$, perceived stress will be positively and indirectly related to depression through SOC as a mediator (MacKinnon and Luecken, 2008; MacKinnon and Luecken, 2011; MacKinnon and Pirlott, 2014). (shown in Fig. 1)

\section{Methods}

\subsection{Design and participants}

The study was conducted using a cross-sectional survey among older stroke patients. Inclusion criteria were: (1) $\geq 60$ years old; (2) had a primary clinical diagnosis of stroke; (3) confirmed by CT and MRI; (4) within the last 7-30 days of stroke (Li et al., 2016). Exclusion criteria were: (1) severe aphasia and attention dysfunction; (2) severe cognition dysfunction (the Mini Mental State Examination score less than10(Tombaugh and McIntyre, 1992); (3) diagnosed mental disorder; (4) serious illness and required critical care.

\subsection{Measurements}

The questionnaire included demographic variables such as age, gender, height, weight, body mass index (BMI), spouse status, education status, alcohol drinking habits, smoking habits, hypertension, diabetes, coronary heart disease (CHD) and hyperlipemia status, contact information, and the three previously validated questionnaires SOC, the Perceived Stress Scale (PSS), the Center for Epidemiologic Studies Depression Scale (CES-D) and the Perceived Stress Scale (PSS).

Sense of Coherence Scale

The Sense of Coherence (SOC) scale was developed from interviews with people who had recovered from adverse experiences, consisting of comprehensibility, manageability, and meaningfulness (Antonovsky, 1987). The original scale comprised of 29 items, but recently the 13-item version has become popular and was utilized (Antonovsky, 1993). This is a seven-point Likert scale, with item ranges of 1-7 for total scores ranging from 13 to 91 . The higher the total score, the stronger the SOC. In the present study, the Cronbach's alpha was 0.924 .

Depression symptoms

Depressive symptoms were screened using the Chinese version of the CES-D. 
This has been widely used to measure depression in China and is highly reliable and valid (Liu, et al., 2012). Twenty individual items generate four subscales: depressed affect, positive affect, somatic, and retarded activity and interpersonal problems (Radloff, et al., 1977). It is a four-point Likert scale. Each item of the CES-D is scored between 0 (rarely or not at all) and 3 (most or all of the time) which describe how often the respondents had each feeling in the past week. The total score ranges from 0 to 60 , and higher scores indicate the severity of depression. The respondents are considered depressed if they score a CES-D greater than 16. In the present study, the Cronbach's alpha was 0.886 .

Perceived Stress

Perceived stress was measured with the PSS scale which assessed the extent to which respondents feel that their stress is unpredictable, uncontrollable, and overwhelming. The reliability and validity of the PSS has been previously documented in China (Liu et al., 2017; Yang and Huang, 2003). This instrument consists of 14 items and two subscales: sense of being out of control and feeling of tension. The PSS is a five-point Likert scale, on which every item is scored from 1 (strongly disagree) to 5 (strongly agree), the total score ranges from 14 to 70 , and the higher scores indicate a higher level of stress. In the present study, the Cronbach's alpha was 0.832 .

\subsection{Ethics}

The study was approved by the Ethical Review Board of the first affiliated Hospital of Zhengzhou University, Zhengzhou, Henan Province, China. All participants were informed about the study and informed consent was obtained before data collection, and the study procedures were in accordance with ethical standards (World Medical Association, 2001).

\subsection{Data collection}

A cross-sectional survey was conducted in Henan Province (population 95 million), China, during July 2016-July 2017. First, one city was randomly selected in each region (eastern, western, southern, northern and central) of Henan, one hospital was randomly selected from several hospitals where the beds are greater than 500 in each city. Then in the capital city two hospitals were selected from several hospitals 
where the beds are greater than 2500. In total, six large general hospitals were selected from five cities.

The investigators were uniformly trained and a one-to-one, face-to-face data collection method was used. A convenience sample of older stroke patients was recruited from Neurology wards from each hospital, and 3000 older stroke patients took part in the survey, with 2907 individuals completing the study (response rate: $96.90 \%)$.

\subsection{Data analysis}

Data analysis was performed with SPSS version 21.0 (IBM Corporation, Armonk, NY, USA), AMOS22.0 (IBM Corporation, Armonk, NY, USA) and Microsoft Excel, 2003. $P<0.05$ was regarded as the difference is statistical significance.

Descriptive statistics for demographic variables, perceived stress, sense of coherence, and depression scores were presented using frequencies, percentages, means, and standard deviations.

Pearson's rank correlation coefficients were used to examine the relationship among the perceived stress, sense of coherence, and depression dimensions.

Multiple linear regression was used to evaluate whether perceived stress and sense of coherence could significantly affect the outcome variable of depression. Epidemiological investigations of depression among the elderly in Chinese (Liu et al., 2017) and Turkey (Arslantas et al., 2014) showed that gender, age, spouse status and education status are closely related to the prevalence of depression. Thus, four demographic variables (i.e. sex, age, spouse status, and education status) were admitted in Model 1 to control for their effects; then, Model 2 was built with perceived stress dimensions added on the basis of Model 1. And finally, Model 3 was established with sense of coherence dimensions added on the basis of Model 2.

Then, we employed a structural equation modeling approach (using AMOS version 22.0) with the widely used bootstrap method (Kenneth and Robert, 1990; Hayes 2009), to confirm the hypothetical relationship among perceived stress, sense of coherence, and depression. 


\section{Results}

\subsection{The sample}

Of the 2907 older stroke patients, the ages ranged from 60 to 89 , with a mean age of $68.64 \pm 6.83$ years, and the mean body mass index was $20.53 \pm 3.71 \mathrm{~kg} / \mathrm{m}^{2}$. Table 1 provides further characteristics of the participants.

\subsection{Description of the three scales}

The mean score of PSS, SOC and CES-D were $29.62 \pm 8.73,74.47 \pm 8.59$ and $13.60 \pm 4.04$, respectively. In addition, the minimum, maximum and mean score of each scale and their subscales are shown in Table 2.

\subsection{Pearson's rank Correlation Analyses}

The results of the Pearson's rank Correlation Analyses indicated that: there was a negative correlation between the total score of the sense of coherence and the total score of the perceived stress $(r=-0.80, P<0.01)$, and was all also a negative correlation between the subscales score of SOC and the subscales score of PSS $r=$ -0.65 to $-0.57, P<0.01)$; there was a negative correlation between the total score of the sense of coherence and the total score of the depression $(r=-0.77, P<0.01)$, and was also a negative correlation between the subscales score of SOC and the subscales score of CES-D ( $r=-0.56$ to $-0.34, P<0.01$ ); there was a positive correlation between the total score of the perceived stress and the total score of depression $(r=0.82, P<0.01)$, and were a positive correlations between the subscales score of PSS and the subscales score of CES-D ( $r=0.42$ to $0.66, P<0.01)$. See Table 3.

\subsection{Multiple Regression Analyses}

With depression as the dependent variable and demographic variables as the controlled variables, the perceived stress and sense of coherence dimensions were taken as principal predictors by a thrice repeated multiple linear regression analysis.

As shown in Table 4, Model $1\left(F=61.829, P<0.01\right.$, adjusted $\left.R^{2}=0.033\right)$ accounted for a significant portion of the variance in depression. This indicated that these demographic variables could explain $7.7 \%$ of the variation in depression, and age, gender and spouse states were significant predictors. 
When perceived stress dimensions as independent variable was added in Model 2 ( $F=1004.612, P<0.01$, adjusted $\left.R^{2}=0.674\right)$ on the basis of Model 1 , these independent variables jointly accounted for $67.4 \%$ variation of depression, $59.7 \%$ of which was explained by these additional variables. Significant predictors of these variables entered in Model 2 were spouse status, sense of being out of control and feeling of tension. Age and gender were no longer a significant predictor, Table 4.

With sense of coherence dimensions added in Model 3 ( $F=813.285, P<0.01$, adjusted $R^{2}=0.716$ ), the influence of perceived stress on depression declined from 0.469 to 0.309 in the sense of being out of control dimension (decreased by16.0\%) and from 0.416 to 0.293 in the feeling of tension dimension (decreased by $12.3 \%$ ), see Table 4; and the multiple linear regression accounted for $71.6 \%$ variance of depression, a total of $4.2 \%$ of which was explained by these additional variables (Table 4).

\subsection{Structural Equation Model Confirmed Analyses}

To confirm the significance of the direct, indirect, and total effects in a mediation model, the standardized structural equation modeling including three latent variables is shown in Fig. 2, and the modified goodness-of-fit indexes showed the mediation model fitted the data well in Table 5.

The structural equation modeling explained $18 \%$ of the variance in sense of coherence index and $83 \%$ of the variance in depression according to the estimated squared multiple correlations of two endogenous latent variables. The two factor-loading parameters $(0.82-0.84)$ in the perceived stress matrix, the three factor-loading parameters $(0.85-0.90)$ in the sense of coherence matrix and the four factor-loading parameters $(0.28-0.53)$ in depression matrix all reached significance $(\mathrm{P}$ $<0.01)$. Through path analysis, the path coefficient of direct effect of perceived stress on depressive symptoms was 0.73 , after sense of coherence added, the path coefficient of perceived stress on the depressive symptoms decreased from 0.73 to $0.130(-0.42 \times$ $-0.31)$.

The standardized direct, indirect, and total effect of perceived stress and sense of coherence on depression is presented in Table 6. The results demonstrated that perceived stress had a significant direct effect on depression $\left(\mathrm{H}_{1}\right)$ and sense of 
coherence $\left(\mathrm{H}_{2}\right)$. Meanwhile, sense of coherence had a significant direct effect on depression $\left(\mathrm{H}_{3}\right)$. The bootstrapped 95\% confidence interval (CI) confirmed that the indirect effect of sense of coherence in the relationship between perceived stress, and depression was significant $\left(\mathrm{H}_{4}\right)$. This also indicated that $15.5 \%(0.134 / 0.866)$ of the total effect on depression was produced by sense of coherence as a partial mediator.

\section{Discussion}

The frequency of older stroke patients with risk of depression was $30.2 \%$ in the present study, which was similar to previous research showing the prevalence of post-stroke depression varying from 5\% to 54\% (Kouwenhoven, et al., 2011; Shi et al., 2017; Xu et al., 2011). Thus approximately one-third of all stroke survivors suffer late-life mood disorders. The prevalence of post-stroke depression depends on many factors, such as older age, female gender, having no spouse, and lower education status (Liu et al., 2017; Arslantas et al., 2014) In the present study, age, gender and spouse status were significant predictors of depressive symptoms in Model 1; however, age and gender became no longer significant in Model 2, and spouse status became no longer significant in Model 3. This indicated that these variables may exert effect on depression via perceived stress or sense of coherence among older stroke patients. van der Waerden (2014) also reported that perceived stress mediated the relationship between low socioeconomic status and depressive symptoms. The present study also found that although education status was no significant predictor in Model 1 or Model 2, it became significant in Model 3. This revealed that education exerts effect on depression combined with sense of coherence.

In terms of the correlation between perceived stress, sense of coherence and depression among older stroke patients, all dimensions of perceived stress were proved to be negatively and significantly associated with sense of coherence. All dimensions of sense of coherence were verified to be negatively and significantly associated with depression; and all dimensions of perceived stress were significantly and positively associated with depression. Thus, the greater perceived stress, the more risk of depression; the greater sense of coherence, the less risk of depression, which was 
consistent with Beam et al.(2017) and Li et al. (2015).

Results of Model 2 showed that two dimensions (sense of being out of control and feeling of tension) of perceived stress had a significant impact on depression under the control of demographic variables. Previous two studies on older adults conducted by Tsai et al (Tsai et al., 2015 ) Liu et al (2017) have also shown that perceived stress may bring forth even higher risk for depression by eroding their sense of personal control and self-worth, which is similar to the present study. After the sense of coherence dimensions were included in Model 3, 4.2\% of the explanation of independent variables on depression was increased, moreover, however, the influence of sense of being out of control on depression was decreased by $16.0 \%$ and feeling of tension was decreased by $12.3 \%$. Thus, we inferred that perceived stress would pose an indirect effect on depression through manageability, comprehensibility and meaningfulness of sense of coherence, and faced with the same pressures, individuals with high levels of sense of coherence were less likely to have depression.

Further, structural equation modeling was employed to verify the hypothetical relationship, which is shown in Fig. 4. According to the goodness-of-fit indexes, the structural equation modeling analysis of the effect of perceived stress on depression with sense of coherence as a mediator indicated that the data entirely supports the theoretical model. Moreover, Table 6 confirmed that perceived stress had a positive and indirect effect on depression through sense of coherence.

All results confirmed that perceived stress has a direct effect on sense of coherence and that a high level of perceived stress negatively impacts sense of coherence, and the poorer sense of coherence, thereby increasing the possibility of depression, which was consistent with Neuman 's systems model theory. Neuman (Neuman, and Fawcett, 2002) state that when stressors act on the body, the flexible line of defense plays a protective buffer role, once the defense line is damaged, the body will produce a stress reaction, and negative stress may lead to emotional problems, such as anxiety and depression. The sense of coherence is similar to the flexible line of defense, therefore perceived stress can cause depression by destroying the sense of coherence. 
In the face of unchangeable pressure, individuals can have a good buffer and coordination with a higher level of sense of coherence. Antonovsky (1987) hypothetically claimed that SOC is a rather stable quality of an individual after 30 years of age, however, some new researchers (Sagy and Antonovsky, 2000; Vastamäki et al., 2009; Yamazaki et al., 2011; Kähönen et al., 2012) present interesting results indicating that SOC is more dynamic than formerly believed and empirical evidence reveals that SOC may be improved due to a mode of therapy. Therefore, relevant interventions should be implemented to enhance the sense of coherence and withstand the occurrence and destroy perceived stress. We can intervene in patients after stroke according to three aspects of sense of coherence:(1) Comprehensibility refers to the stimuli deriving from one's internal and external environments in the course of living are structured, predictable, ordered, clear, and explicable; (2) Manageability is to the extent that resources are at their disposal and are adequate to meet the demands posed by the stimuli; (3) Meaningfulness refers to the extent to which a person feels that these demands are challenges that are worthy of investment and engagement (Antonovsky, 1987; Antonovsky, 1993; Pretty et al., 2014; Würtz et al., 2015). According to these three aspects, we can intervene in older stroke patients as following:(1) Teach and help patients to understand the risk factors, the pathogenesis and the treatment of stroke, and persuade them to know the event in terms of cognition and emotion, and accept it; (2) Prompt them to make full use of surrounding resources and take active measures to deal with the difficulties brought on by stroke, and encourage their friends and relatives to participate in the management of the disease, make them believe that the disease can be prevented, treated and controlled; (3) Actively support and guide their medication use and rehabilitation exercises, and help them to understand that positive coping and controlled stress from stroke is valuable and meaningful to health and life.

This study has some limitations: (1) the participants were limited to Henan province, although there is a good representation, however it still does not represent the situation in other regions, therefore a larger and more diverse sample is required for further study; (2) the study only carried out the exploration of the preliminary theory 
about the mediating effect of sense of coherence, but did not put forward more specific interventions for older stroke patients on strengthening the sense of coherence, hence, future studies should develop a more thorough and particular intervention index system on strengthening the sense of coherence; (3) this study found that sense of coherence only partially mediates the association between perceived stress and depression, concluding that other factors can be acted as mediators. Therefore, future studies should examine additional mediators to provide a wide perspective on the complex relationship between perceived stress and depression among the older stroke patients.

\section{Conclusion}

Sense of Coherence is the mediating variable between perceived stress and depression. Sense of Coherence may cause the negative influence that perceived stress has on depression. Actively exploring interventions to improve sense of coherence and promote the construction and development of the intervention index system will not only help healthcare staff to offer health education to old stroke patients, but also help old stroke patients themselves to maintain physical and mental health, thereby help to reduce the occurrence of the depression of old stroke patients. 


\section{References}

Alajbegovic, A., Djelilovic-Vranic, J., Alajbegovic, S., Nakicevic, A., Todorovic, L., \& Tiric-Campara, M. (2014). Post stroke depression. Medical archives, 68(1), 47.

Antonovsky, A. (1987). Unraveling the mystery of health: How people manage stress and stay well. Jossey-bass.

Arslantas, D., Ünsal, A., \& Ozbabalık, D. (2014). Prevalence of depression and associated risk factors among the elderly in M iddle A natolia, T urkey. Geriatrics \& gerontology international, 14(1), 100-108.

Beam, C. R., Dinescu, D., Emery, R., \& Turkheimer, E. (2017). A twin study on perceived stress, depressive symptoms, and marriage. Journal of health and social behavior, 58(1), 37-53.

Bollen, K. A., \& Stine, R. (1990). Direct and indirect effects: Classical and bootstrap estimates of variability. Sociological methodology, 115-140.

Cameron, J. I., Stewart, D. E., Streiner, D. L., Coyte, P. C., \& Cheung, A. M. (2014). What makes family caregivers happy during the first 2 years post stroke?. Stroke, 45(4), 1084-1089.

De Ryck, A., Brouns, R., Geurden, M., Elseviers, M., De Deyn, P. P., \& Engelborghs, S. (2014). Risk factors for poststroke depression: identification of inconsistencies based on a systematic review. Journal of geriatric psychiatry and neurology, 27(3), 147-158.

Dou, J., Tang, J., Lu, C. H., Jiang, E. S., \& Wang, P. X. (2015). A study of suicidal ideation in acute ischemic stroke patients. Health and quality of life outcomes, 13(1), 7.

Eriksson, M., \& Lindström, B. (2006). Antonovsky's sense of coherence scale and the relation with health: a systematic review. Journal of Epidemiology \& Community Health, 60(5), 376-381.

Feigin, V. L., Forouzanfar, M. H., Krishnamurthi, R., Mensah, G. A., Connor, M., Bennett, D. A., et al. (2014). Global and regional burden of stroke during 1990-2010: findings from the Global Burden of Disease Study 2010. The Lancet, 383(9913), 245-255. 
Fonarow, G. C., Smith, E. E., Saver, J. L., Reeves, M. J., Bhatt, D. L., Grau-Sepulveda, M. V., et al.(2011). Timeliness of tissue-type plasminogen activator therapy in acute ischemic stroke. Circulation, 123(7), 750-758.

Guo, L. N., Zauszniewski, J. A., Ding, X. F., Liu, Y. C., Huang, L. J., \& Liu, Y. J. (2017). Psychometric Assessment of the Depressive Cognition Scale Among Older Chinese People. Archives of Psychiatric Nursing, 31(5),477-482.

Hackett, M. L., \& Pickles, K. (2014). Part I: frequency of depression after stroke: an updated systematic review and meta-analysis of observational studies. International Journal of Stroke, 9(8), 1017-1025.

Hadidi, N., Treat-Jacobson, D. J., \& Lindquist, R. (2009). Poststroke depression and functional outcome: a critical review of literature. Heart \& Lung: The Journal of Acute and Critical Care, 38(2), 151-162.

Hayes, A. F. (2009). Beyond Baron and Kenny: Statistical mediation analysis in the new millennium. Communication monographs, 76(4), 408-420.

KÄHÖNEN, K., NÄÄTÄNEN, P., Tolvanen, A., \& SALMELA - ARO, K. A. T. A. R. I. I. N. A. (2012). Development of sense of coherence during two group interventions. Scandinavian Journal of Psychology, 53(6), 523-527.

Karakus, K., Kunt, R., Memis, C. O., Kunt, D. A., Dogan, B., Ozdemiroglu, F., \& Sevincok, L. (2017). The factors related to early - onset depression after first stroke. Psychogeriatrics, 17(6), 414-422.

Koelen, M., Eriksson, M., \& Cattan, M. (2017). Older people, sense of coherence and community. In The Handbook of Salutogenesis (pp. 137-149). Springer, Cham.

Kouwenhoven, S. E., Kirkevold, M., Engedal, K., \& Kim, H. S. (2011). Depression in acute stroke: prevalence, dominant symptoms and associated factors. A systematic literature review. Disability and rehabilitation, 33(7), 539-556.

Kutlubaev, M. A., \& Hackett, M. L. (2014). Part II: predictors of depression after stroke and impact of depression on stroke outcome: an updated systematic review of observational studies. International Journal of Stroke, 9(8), 1026-1036.

Laures-Gore, J. S., \& DeFife, L. C. (2013). Perceived stress and depression in left and right hemisphere post-stroke patients. Neuropsychological rehabilitation, 23(6), 
783-797.

Li, W., Leonhart, R., Schaefert, R., Zhao, X., Zhang, L., Wei, J., , et al. (2015). Sense of coherence contributes to physical and mental health in general hospital patients in China. Psychology, health \& medicine, 20(5), 614-622.

Li, J., Oakley, L. D., Brown, R. L., Li, Y., Ye, M., \& Luo, Y. (2016). Early symptom measurement of Post-Stroke Depression (PSD). Journal of affective disorders, 197, 215-222.

Liu, L., Chang, Y., Fu, J., Wang, J., \& Wang, L. (2012). The mediating role of psychological capital on the association between occupational stress and depressive symptoms among Chinese physicians: a cross-sectional study. $B M C$ public health, 12(1), 219.

Liu Y., Guo L., \& Liu K. (2016). Relationship between depression level and perceived stress among the elderly in community: Moderating effect and mediating effect. Chinese Mental Health Journal, 30(8), 608-611.(In Chinese)

Liu, Y., Li, T., Guo, L., Zhang, R., Feng, X., \& Liu, K. (2017). The mediating role of sleep quality on the relationship between perceived stress and depression among the elderly in urban communities: a cross-sectional study. Public health, 149, 21-27.

MacHale, S. M., O’Rourke, S. J., Wardlaw, J. M., \& Dennis, M. S. (1998). Depression and its relation to lesion location after stroke. Journal of Neurology, Neurosurgery \& Psychiatry, 64(3), 371-374.

MacKinnon, D. P., \& Luecken, L. J. (2008). How and for whom? Mediation and moderation in health psychology. Health psychology, 27(2S), S99.

MacKinnon, D. P., \& Luecken, L. J. (2011). Statistical analysis for identifying mediating variables in public health dentistry interventions. Journal of Public Health Dentistry, 71, S37-S46.

MacKinnon, D. P., \& Pirlott, A. G. (2015). Statistical approaches for enhancing causal interpretation of the M to Y relation in mediation analysis. Personality and Social Psychology Review, 19(1), 30-43.

Neuman, B. M., \& Fawcett, J. (2002). The Neuman systems model. Pearson Education, 
Incorporated. Pretty, G. H., Chipuer, H. M., \& Bramston, P. Sense of Coherence. identity, 23, 273-287.

Wang, Y., Liao, X., Zhao, X., Wang, D. Z., Wang, C., Nguyen-Huynh, M. N., et al. (2011). Using recombinant tissue plasminogen activator to treat acute ischemic stroke in China: analysis of the results from the Chinese National Stroke Registry (CNSR). Stroke, 42(6), 1658-1664.

Radloff, L. S. (1977). The CES-D scale: A self-report depression scale for research in the general population. Applied psychological measurement, 1(3), 385-401.

Robinson, R. G., \& Jorge, R. E. (2015). Post-stroke depression: a review. American Journal of Psychiatry, 173(3), 221-231.

Sagy, S., \& Antonovsky, H. (2000). The development of the sense of coherence: A retrospective study of early life experiences in the family. The International Journal of Aging and Human Development, 51(2), 155-166.

Shi, Y., Yang, D., Zeng, Y., \& Wu, W. (2017). Risk factors for post-stroke depression: a meta-analysis. Frontiers in aging neuroscience, 9, 218.

Tan, K. K., Chan, S. W. C., Wang, W., \& Vehviläinen-Julkunen, K. (2016). A salutogenic program to enhance sense of coherence and quality of life for older people in the community: A feasibility randomized controlled trial and process evaluation. Patient education and counseling, 99(1), 108-116.

Tombaugh, T. N., \& McIntyre, N. J. (1992). The mini - mental state examination: a comprehensive review. Journal of the American Geriatrics Society, 40(9), 922-935.

Tsai, A. C., Chi, S. H., \& Wang, J. Y. (2015). Association of perceived stress with depressive symptoms in older $\mathrm{T}$ aiwanese: Results of a population-based study. Geriatrics \& gerontology international, 15(5), 535-543.

van der Waerden, J. E., Hoefnagels, C., Hosman, C. M., \& Jansen, M. W. (2014). Defining subgroups of low socioeconomic status women at risk for depressive symptoms: the importance of perceived stress and cumulative risks. International Journal of Social Psychiatry, 60(8), 772-782.

Vastamäki, J., Moser, K., \& Paul, K. I. (2009). How stable is sense of coherence? 
Changes following an intervention for unemployed individuals. Scandinavian journal of psychology, 50(2), 161-171.

van der Waerden, J. E., Hoefnagels, C., Hosman, C. M., \& Jansen, M. W. (2014). Defining subgroups of low socioeconomic status women at risk for depressive symptoms: the importance of perceived stress and cumulative risks. International Journal of Social Psychiatry, 60(8), 772-782.

World Medical Association. (2013). World Medical Association Declaration of Helsinki: ethical principles for medical research involving human subjects. Jama, 310(20), 2191.

Würtz, E. T., Fonager, K., \& Mortensen, J. T. (2015). Association between sense of coherence in adolescence and social benefits later in life: a 12-year follow-up study. BMJ open, 5(1), e006489.

Xu, X.M., Zou, D.Z., Shen, L.Y., Liu, Y., Zhou, X. Y., Pu, J. C., et al. Efficacy and feasibility of antidepressant treatment in patients with post-stroke depression. Medicine,2016, 95(45).

Yamazaki, Y., Togari, T., \& Sakano, J. (2011). Toward development of intervention methods for strengthening the sense of coherence: suggestions from Japan. In Asian perspectives and evidence on health promotion and education (pp. 118-132). Springer, Tokyo.

Yang, T. Z., \& Huang, H. T. (2003). An epidemiological study on stress among urban residents in social transition period. Zhonghua liu xing bing xue za zhi, 24(9), 760-764.

Yang, G., Wang, Y., Zeng, Y., Gao, G. F., Liang, X., Zhou, M., et al. (2013). Rapid health transition in China, 1990-2010: findings from the Global Burden of Disease Study 2010. The lancet, 381(9882), 1987-2015.

Zhou, Y., Xu, Z., Liao, J., Feng, F., Men, L., Xu, L., et al. (2017). New standardized nursing cooperation workflow to reduce stroke thrombolysis delays in patients with acute ischemic stroke. Neuropsychiatric disease and treatment, 13, 1215. 

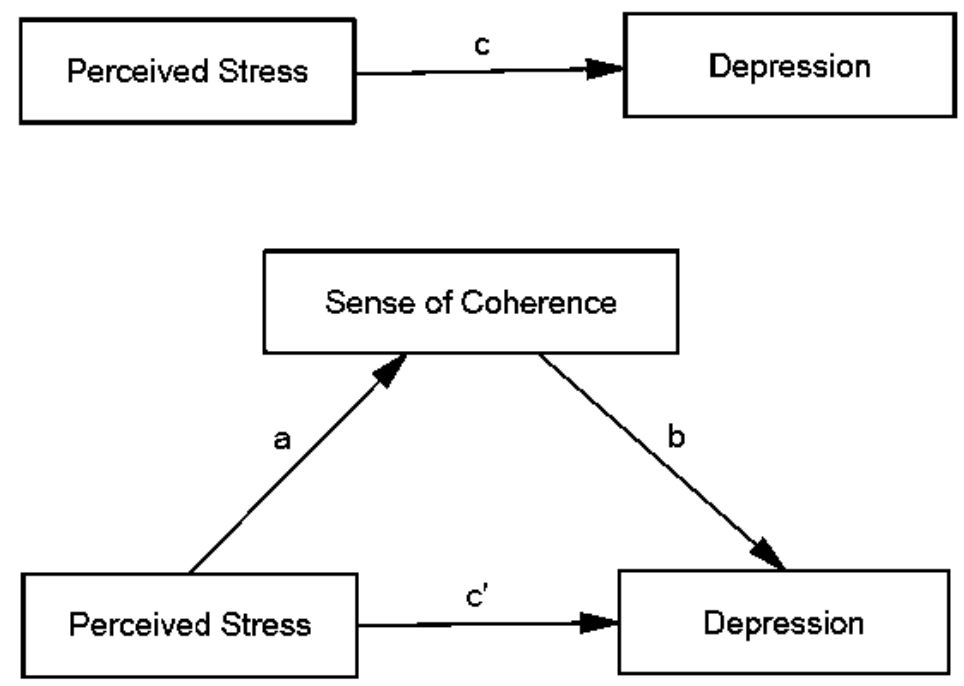

Fig.1. Theoretical model of the mediating role of sense of coherence on the association between perceived stress and depression.
c: Associations of perceived stress with depression;
a: Associations of perceived stress with sense of coherence;
$\mathrm{b}$ : Association between sense of coherence and depression after controlling for the predictor variables;
$c^{\prime}$ : Associations of perceived stress with depression after adding sense of coherence as a mediator. 


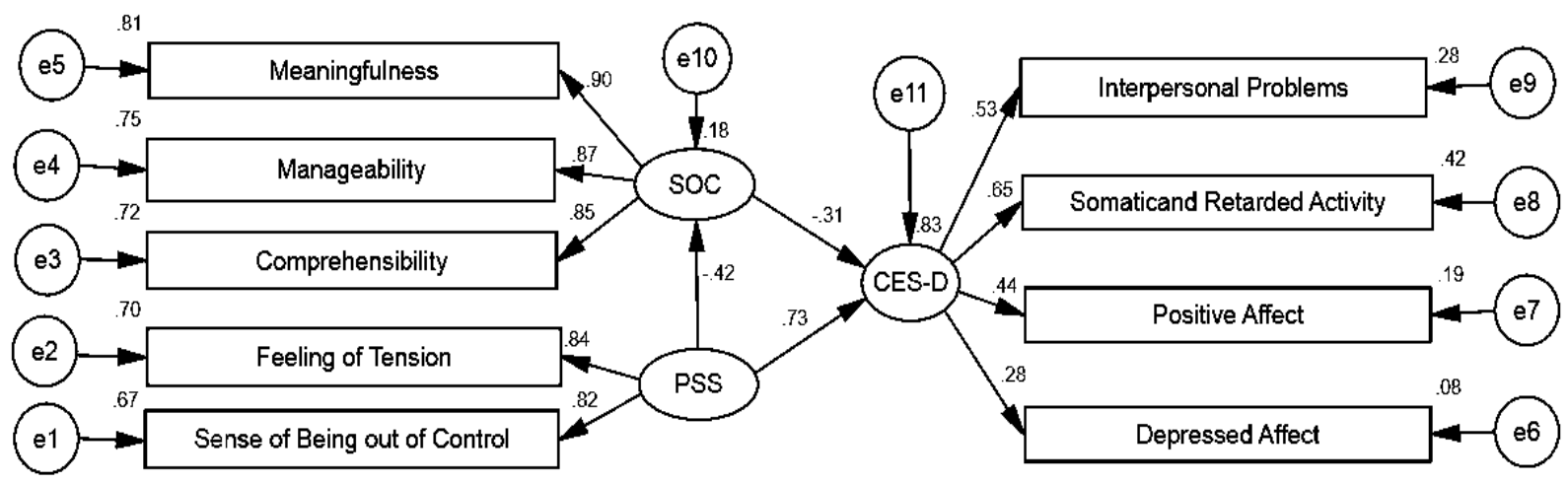

Fig.2. The standardized structural equation model on the relationship among perceived stress, the sense of coherence, and depressive symptoms $(n=2907)$

PSS, the Perceived Stress Scale; SOC, The Sense of Coherence; CES-D, the Center for Epidemiologic Studies Depression Scale. e1-e9, the measurement error of each observed variable to estimate latent variables; e10-e11: the residual that may affect the endogenous latent variables except the exogenous latent variables. 
Table 1 Characteristics of the sample $(n=2907)$

\begin{tabular}{|c|c|c|}
\hline Variables & Group & $\mathrm{n}(\%)$ \\
\hline \multirow[t]{5}{*}{ City } & Zhengzhou & $964(33.2)$ \\
\hline & Shangqiu & $481(16.5)$ \\
\hline & Zhumadian & $478(16.4)$ \\
\hline & Luoyang & 493(17.0) \\
\hline & Hebi & 491(16.9) \\
\hline \multirow[t]{3}{*}{ Age in years } & $60-70$ years old $(N / \%)$ & $1136(39.1)$ \\
\hline & $\geq 70$ years old $(N / \%)$ & $1717(59.1)$ \\
\hline & $\geq 80$ years old & $54(1.8)$ \\
\hline \multirow[t]{2}{*}{ Gender } & Male & $1416(48.7)$ \\
\hline & Female & 1491(51.3) \\
\hline \multirow[t]{2}{*}{ Spouse states } & Have & $2277(78.3)$ \\
\hline & no & $630(21.7)$ \\
\hline \multirow[t]{5}{*}{ Education status } & Elementary school or less & $589(20.3)$ \\
\hline & Middle school & $1420(48.8)$ \\
\hline & High school & $379(13.0)$ \\
\hline & Professional education & $259(8.9)$ \\
\hline & Undergraduate or more & $260(8.9)$ \\
\hline \multirow[t]{2}{*}{ Smoking status } & Yes & $895(30.8)$ \\
\hline & No & $2012(69.2)$ \\
\hline moderate or heavy alcohol consumption status $(\geqslant 2$ standard & Yes & $146(5.0)$ \\
\hline alcoholic beverages consumed per day) & No & 2761(95.0) \\
\hline \multirow[t]{3}{*}{$\mathrm{BMI}(\mathrm{Mean} \pm \mathrm{SD})$} & $<18.5 \mathrm{~kg} / \mathrm{m}^{2}$ & $209(7.2)$ \\
\hline & $18.5-22.9 \mathrm{~kg} / \mathrm{m}^{2}$ & $2506(86.2)$ \\
\hline & $>22.9 \mathrm{~kg} / \mathrm{m}^{2}$ & 192(6.6) \\
\hline \multirow[t]{2}{*}{ Hypertension status } & Have & $1195(41.1)$ \\
\hline & No & 1712(58.9) \\
\hline \multirow[t]{2}{*}{ Diabetes status } & Have & $1227(42.2)$ \\
\hline & No & $1680(57.8)$ \\
\hline \multirow[t]{2}{*}{ coronary heart disease(CHD) } & Have & $416(14.3)$ \\
\hline & No & 2491(85.7) \\
\hline \multirow[t]{2}{*}{ Hyperlipemia status } & Have & $1331(45.8)$ \\
\hline & No & $1576(54.2)$ \\
\hline
\end{tabular}

BMI, body mass index. 
Table 2 Description of PSS, SOC and CES-D(n=2907)

\begin{tabular}{cccc}
\hline Variables & Range of score & Mean & Standard Deviation \\
\hline PSS & $\mathbf{1 4 - 6 2}$ & $\mathbf{2 9 . 6 2}$ & $\mathbf{8 . 7 3}$ \\
Sense of being out of control & $7-31$ & 14.47 & 4.60 \\
Feeling of tension & $7-32$ & 15.14 & 4.89 \\
SOC & $\mathbf{3 8 - 9 0}$ & $\mathbf{7 4 . 4 7}$ & $\mathbf{8 . 5 9}$ \\
Comprehensibility & $8-35$ & 28.36 & 4.30 \\
Manageability & $7-28$ & 23.05 & 3.51 \\
Meaningfulness & $12-28$ & 23.06 & 3.51 \\
CES-D & $\mathbf{1 - 4 6}$ & $\mathbf{1 3 . 6 0}$ & $\mathbf{4 . 0 4}$ \\
Somatic and retarded activity & $0-18$ & 6.57 & 2.76 \\
Positive affect & $0-12$ & 3.11 & 2.11 \\
Depressed affect & $0-17$ & 2.71 & 0.82 \\
Interpersonal problems & $0-6$ & 1.21 & 0.63 \\
\hline
\end{tabular}

PSS, the Perceived Stress Scale; SOC, The Sense of Coherence Scale; CES-D, the Center for Epidemiologic Studies Depression Scale. 
Table 3 The Pearson's rank correlation coefficients of three scales $(n=2907)$

\begin{tabular}{|c|c|c|c|c|c|c|c|c|c|c|c|c|}
\hline Variables & 1 & 2 & 3 & 4 & 5 & 6 & 7 & 8 & 9 & 10 & 11 & 12 \\
\hline 1 PSS & - & & & & & & & & & & & \\
\hline 2 Sense of being out of control & $0.92^{*}$ & - & & & & & & & & & & \\
\hline 3 Feeling of tension & $0.93^{*}$ & $0.69^{*}$ & - & & & & & & & & & \\
\hline $4 \mathrm{SOC}$ & $-0.80^{*}$ & $-0.70^{*}$ & $-0.76^{*}$ & - & & & & & & & & \\
\hline 5 Comprehensibility & $-0.66^{*}$ & $-0.57^{*}$ & $-0.65^{*}$ & $0.87^{*}$ & - & & & & & & & \\
\hline 6 Manageability & $-0.66^{*}$ & $-0.60^{*}$ & $-0.62^{*}$ & $0.83^{*}$ & $0.53^{*}$ & - & & & & & & \\
\hline 7 Meaningfulness & $-0.65^{*}$ & $-0.58^{*}$ & $-0.62^{*}$ & $0.76^{*}$ & 0.51 * & $0.52^{*}$ & - & & & & & \\
\hline 8 CES-D & $0.82^{*}$ & $0.75^{*}$ & $0.76^{*}$ & $-0.77^{*}$ & -0.66 & $-0.61^{*}$ & $-0.64^{*}$ & - & & & & \\
\hline 9 Somatic and Retarded activity & 0.71 * & $0.65^{*}$ & $0.66^{*}$ & $-0.65^{*}$ & $-0.56^{*}$ & $-0.53^{*}$ & $-0.53^{*}$ & $0.90^{*}$ & - & & & \\
\hline 10 Depressed affect & $0.46^{*}$ & $0.43^{*}$ & $0.42^{*}$ & $-0.45^{*}$ & $-0.40^{*}$ & $-0.34^{*}$ & $-0.39^{*}$ & $0.68^{*}$ & $0.43^{*}$ & - & & \\
\hline 11 Positive affect & $0.65^{*}$ & 0.58 * & $0.62^{*}$ & $-0.64^{*}$ & $-0.56^{*}$ & $-0.50^{*}$ & $-0.53^{*}$ & $0.66^{*}$ & $0.47^{*}$ & $0.20^{*}$ & - & \\
\hline 12 Interpersonal problems & $0.57^{*}$ & 0.51 * & $0.54^{*}$ & $-0.50^{*}$ & $-0.42^{*}$ & $-0.42^{*}$ & $-0.43^{*}$ & 0.63 * & $0.49^{*}$ & $0.35^{*}$ & $0.33^{*}$ & - \\
\hline
\end{tabular}

PSS, the Perceived Stress Scale; SOC, the Sense of Coherence Scale; CES-D, the Center for Epidemiologic Studies Depression Scale. ${ }^{*} P<0.01$. 
Table 4 Results of the multiple regression analysis by building progressive models with depression as the dependent variable $(n=2907)$

\begin{tabular}{|c|c|c|c|c|c|c|c|}
\hline Models & variables & $B(S E)$ & Beta & $t$ & $P$ & $F$ & $\begin{array}{c}\text { Adjusted } \\
R^{2}\end{array}$ \\
\hline \multirow[t]{4}{*}{ Modell } & Age & $0.112(0.019)$ & 0.112 & 5.982 & 0.000 & $61.829^{*}$ & 0.077 \\
\hline & Gender & $0.808(0.329)$ & 0.045 & -2.453 & 0.014 & & \\
\hline & Spouse states & $4.926(0.396)$ & 0.232 & 12.424 & 0.000 & & \\
\hline & Education status & $-0.170(0.141)$ & -0.022 & 1.202 & 0.230 & & \\
\hline \multirow[t]{6}{*}{ Model 2} & Age & $0.021(0.011)$ & 0.021 & -1.854 & 0.064 & $1004.612^{*}$ & 0.674 \\
\hline & Gender & $0.222(0.197)$ & 0.012 & 1.125 & 0.261 & & \\
\hline & Spouse states & $0.989(0.242)$ & 0.047 & 4.091 & 0.000 & & \\
\hline & Education status & $-0.078(0.084)$ & -0.010 & 0.925 & 0.355 & & \\
\hline & Sense of being out of control & $0.817(0.029)$ & 0.469 & 27.953 & 0.000 & & \\
\hline & Feeling of tension & $0.867(0.028)$ & 0.416 & 3.094 & 0.000 & & \\
\hline \multirow[t]{9}{*}{ Model 3} & Age & $0.033(0.011)$ & 0.033 & -3.096 & 0.000 & $813.285^{*}$ & 0.716 \\
\hline & Gender & $0.013(0.185)$ & 0.001 & 0.073 & 0.002 & & \\
\hline & Spouse states & $0.970(0.226)$ & 0.046 & 4.283 & 0.942 & & \\
\hline & Education status & $-0.029(0.079)$ & -0.004 & 0.363 & 0.000 & & \\
\hline & Sense of being out of control & $0.607(0.030)$ & 0.309 & 20.517 & 0.000 & & \\
\hline & Feeling of tension & $0.542(0.031)$ & 0.293 & 17.734 & 0.000 & & \\
\hline & Manageability & $-0.017(0.035)$ & -0.069 & -5.034 & 0.000 & & \\
\hline & Comprehensibility & $-0.379(0.029)$ & -0.181 & -13.279 & 0.000 & & \\
\hline & Meaningfulness & $-0.531(0.047)$ & -0.150 & -11.195 & 0.000 & & \\
\hline
\end{tabular}

Demographic variables were entered as categorical variables, except for age which was entered as a continuous variable. Gender (1:male, 2:female), Spouse states (1:have, 2:no), Education status (1: elementary school or less regularly, 2: middle school,3: high school, 4: professional education, 5: undergraduate or more). ${ }^{*} P<0.01$ 
Table 5. The structural equation model fit measure $(n=2907)$

\begin{tabular}{ccccccccccc}
\hline Index & CMIN/DF & & & & & & & & & \\
& $\left(x^{2} / d f\right)$ & RMR & GFI & AGFI & NFI & IFI & TLI & CFI & RMSEA & PLCODE \\
\hline Statistical value & 2.453 & 0.011 & 0.987 & 0.974 & 0.985 & 0.991 & 0.985 & 0.991 & 0.042 & 0.786 \\
\hline
\end{tabular}

$x^{2}$, chi-square; d.f., degree of freedom; RMR, root mean residual; GFI, goodness of fitness index; AGFI, adjusted goodness of fit index; NFI: normed fit index; IFI: incremental fit index; TLI, Tucker Lewis index; CFI, comparative fit index; RMSEA, root mean square error of approximation; PCLOSE, $P$-value for test of close fit. 
Table 6 The standardized total, indirect, and direct effects of Sense of Coherence on depression with perceived stress as mediator $(n=2907)$

\begin{tabular}{|c|c|c|c|c|c|c|c|}
\hline \multirow{3}{*}{ Model pathways } & \multirow{3}{*}{ Point estimate } & \multirow{2}{*}{\multicolumn{2}{|c|}{ Product of Coefficients }} & \multicolumn{4}{|c|}{ Bootstrapping } \\
\hline & & & & \multicolumn{2}{|c|}{ Percentile 95\% CI } & \multicolumn{2}{|c|}{ Bias-corrected $95 \% \mathrm{CI}$} \\
\hline & & SE & $Z$ & Lower & Upper & Lower & Upper \\
\hline Total effect PSS $\rightarrow$ CES-D & 0.866 & 0.020 & 43.300 & 0.826 & 0.904 & 0.826 & 0.905 \\
\hline Indirect effect PSS $\rightarrow$ CES-D & 0.134 & 0.027 & 4.963 & 0.160 & 0.190 & 0.109 & 0.164 \\
\hline Direct effect PSS $\rightarrow$ CES-D & 0.732 & 0.037 & 14.270 & 0.154 & 0.194 & 0.151 & 0.191 \\
\hline $\mathrm{PSS} \rightarrow \mathrm{SOC}$ & -0.425 & 0.030 & 14.167 & -0.484 & -0.365 & -0.488 & -0.368 \\
\hline $\mathrm{SOC} \rightarrow \mathrm{CES}-\mathrm{D}$ & -0.315 & 0.023 & 13.696 & -0.360 & -0.272 & -0.360 & -0.272 \\
\hline
\end{tabular}

Bootstrap replicates $=2000$; PSS, the Perceived Stress Scale; SOC, The Sense of Coherence; CES-D, the Center for Epidemiologic Studies Depression Scale. 